\title{
E-EDUCAÇÃO E EDUCAÇÃO AMBIENTAL: IMPLICAÇÕES NA CONSTITUIÇÃO DA IDENTIDADE DOCENTE
}

\author{
Eduardo Oliveira Miranda ${ }^{1}$ \\ Jefferson da Silva Moreira² \\ Maria Cecília de Paula Silva ${ }^{3}$
}

\begin{abstract}
Resumo: Com os processos de formação e aprendizagem da docência de futuras pedagogas, originou-se a seguinte problemática: De que forma a oficina Arte-educação e Educação Ambiental pode contribuir nas concepções de meio ambiente de futuras pedagogas do município de Ipirá, Bahia? A proposta da oficina seguiu os princípios da Pesquisa-Ação Participativa (PIMENTA, 2006; BRANDÃO, 2007). Para tal, pautamo-nos nas concepções de Meio Ambiente e Educação Ambiental apresentadas por Reigota (2009) e Medida (1997). A análise dos primeiros achados empíricos leva-nos a afirmar que se faz urgente a amplitude das abordagens que abarquem os aspectos históricos, culturais, políticos e supere a dicotomia homem x natureza.
\end{abstract}

Palavras-chave: Educação Ambiental. Meio Ambiente. Formação Docente.

\section{ART-EDUCATION AND ENVIRONMENTAL EDUCATION: IMPLICATIONS IN THE CONSTITUTION OF THE TEACHING IDENTITY}

\begin{abstract}
With the processes of training and learning teaching of future pedagogies the following problem arose: How can an Art-education and Environmental education office contribute to the environmental conceptions of future pedagogies in the municipality of Ipirá, Bahia? The workshop proposal followed the principles of Participatory Action Research (PIMENTA, 2006; BRANDÃO, 2007). To this end, we are guided by the concepts of Environment and Environmental Education presented by Reigota (2009) and Measure (1997). The analysis of the first empirical findings leads us to affirm that an amplitude of the approaches that cover the historical, cultural, political, and surpasses the dichotomy between man and nature is urgent.

Key words: Environmental Education. Environment. Teachers Formation.
\end{abstract}

\section{CAMINHOS INTRODUTÓRIOS}

$\mathrm{O}$ ato de pesquisar se configura, na atualidade, como um dos elementos necessários da constituição identitária e do desenvolvimento profissional de todo educador que compreenda o seu campo de atuação enquanto lastro de constantes inquietações científicas. Essa busca por respostas se faz urgente, sobretudo na sociedade contemporânea, também denominada de pós-moderna e/ou modernidade tardia, em que os paradigmas são reestruturados com tamanha velocidade, já que a Modernidade Líquida (BAUMAN, 2001) reinterpreta as ações sociais e estabelece o imediatismo característico do capitalismo. O termo paradigma é aqui concebido a partir da análise feita por Thomas Kuhn (1978), que o define como um conjunto de

\footnotetext{
${ }^{1}$ Licenciado em Geografia - Universidade Estadual de Feira de Santana - UEFS. Mestre em Desenho, Cultura e Interatividade - UEFS. Doutorando em Educação - Universidade Federal da Bahia - UFBA.

${ }^{2}$ Licenciado em Pedagogia pela Universidade Estadual de Feira de Santana - UEFS. Mestrando em Educação pelo Programa de Pós-Graduação em Educação - PPGE/UEFS.

${ }^{3}$ Pós-Doutora em sociologia/educação bolsista CAPES, Cooperação Internacional CAPES/COFECUB, Université de Strasbourg.
} 
princípios, normas e valores que orientam a produção do conhecimento em um determinado contexto histórico.

Nesse cenário, somos constantemente bombardeados por ideologias consumistas, as quais repercutem a necessidade da substituição tecnológica em concentrado período da história. Ou seja, consumir na sociedade moderna é a representatividade de inserção social, de acesso aos meios tecnológicos dispostos em larga escala, o que não, necessariamente, está associado à necessidade dos indivíduos partícipes dessas aquisições materiais descontroladas.

Diante dessa problemática social, o currículo escolar, seja da instituição privada, seja pública, em vários momentos, atende às imposições do neoliberalismo ${ }^{4}$ e reforça a ideia de cidadania atrelada ao consumo. Nesse viés, as questões direcionadas à Educação Ambiental e ao Meio Ambiente apontam causas que podem levar a humanidade ao colapso organizacional, já que uma série de transformações acontece em diversas partes do planeta e muitas delas não possuem barreiras físicas, como, por exemplo, as mudanças climáticas, a contaminação dos recursos hídricos, o aumento do efeito estufa e a degradação da camada de ozônio. Outras, por sua vez, afetam com maior evidência grupos sociais específicos e em escalas territoriais bem demarcadas, o que intensifica as desigualdades sociais, a pobreza e a exclusão social.

Para compreender os elementos que ocasionaram essa situação, recorremos às contribuições teóricas tecidas por Camargo (2003), cuja produção elucida que o modelo de sociedade estruturado até o agora se caracteriza pelo modelo urbanoindustrial capitalista, com a forte dicotomia entre homem e natureza, para tal, "a intervenção deliberada e voluntária dos homens sobre a natureza de alguém para torná-la conforme aos valores de sua sociedade" (CHAUÍ, 2003, p. 47). Ainda nessa discussão, recorremos a Loureiro (2003), por apontar que o provável colapso socioambiental pode ter um caminho diferenciado e a escola é uma das instituições sociais adequadas para repensar o caminho no qual nos encontramos. A Educação Ambiental, aliada aos componentes curriculares das escolas, provoca a ressignificação do que entendemos por cidadania, levando em consideração os direitos e os deveres, cujo objetivo central estabelece parâmetros e critérios na construção de uma sociedade sustentável.

\footnotetext{
${ }^{4}$ Sobre como o neoliberalismo age, recorremos a Milton Santos (1996, p. 32): "o neoliberalismo, é frequente o abandono da ideia do nacional brasileiro, com a sedução de um imaginário influenciado por forte apelo da técnica e aceitação tranquila da força totalitária dos fatores da globalização".
} 
A escolha deliberada que o homem optou em se afastar da natureza é fruto da dinâmica cultural. Pensar dessa forma leva-nos a acreditar que a transformação é possível, já que cultura deve ser entendida como mutabilidade, ciclos potenciais em reversibilidades e requer a compreensão de que o aumento da "consciência de incompletude cultural é uma das tarefas prévias à construção de uma concepção emancipadora e multicultural dos direitos humanos" (SANTOS, 2006, p. 446). Trazer os direitos humanos para a discussão é evidenciar a necessidade urgente de refletir e propor ações sustentáveis favoráveis a todos, tanto na dimensão local quanto global, independentemente das diferenças que nos enquadram em classificações socioculturais específicas. Com isso, Boaventura de Sousa Santos (2006 apud SORRENTINO, 2005, p. 287), ressalta que devemos superar essa forma de racionalidade, a qual baseia-se na “erosão da diversidade biológica e cultural, homogeneíza saberes, sabores, paisagens, comportamentos, espécies e raças, por meio do estímulo ao consumismo, da comunicação de massas, da genética e por autoritarismos de todos os tipos".

Portanto, na tentativa de extrapolar as limitações instauradas pelo modo de produção capitalista, vamos, a partir de agora, propor a conceituação de meio ambiente que melhor se encaixa na perspectiva apontada pela concepção emancipadora destacada por Boaventura de Sousa Santos. Destarte, recorremos a Reigota (2009) por verificar que esse autor elucida o entrecruzamento das abordagens humana e da natureza, com dinamicidade aos aspectos culturais, científicos e históricos, ao destacar que meio ambiento é:

O lugar determinado e/ou percebido onde estão em relações dinâmicas e em constante interação os aspectos naturais e sociais. Essas relações implicam processos de criação cultural e tecnológica e processos históricos e sociais de transformação do meio natural e construído (p. 14).

Apesar de não existir um consenso do que seja meio ambiente, pontuaremos as nossas discussões com o viés explicitado por Reigota, por acreditarmos que a relação homem-natureza é traçada por aspectos naturais em complemento aos processos históricos e que desembocam nas formatações das incompletudes culturais. Nesse caminho, temos como prerrogativa a Educação Ambiental enquanto dispositivo indispensável para demarcar ações críticas nos níveis individual e coletivo, nos quais a racionalização na utilização dos recursos oferecidos pelo meio deve ser discutida no campo da abrangência histórica e não apenas pontual. Por isso, as contribuições de Medina (1997) explicitam a seguinte visão sobre a Educação Ambiental: 
Ambiente, para elucidar valores e desenvolver atitudes que lhes permitam adotar uma posição consciente e participativa a respeito das questões relacionadas com a conservação e adequada utilização dos recursos naturais, para a melhoria da qualidade de vida e a eliminação da pobreza extrema e do consumismo desenfreado (p. 16).

Tais considerações elucidadas por Reigota (2009), Medida (1997), Boaventura (2006), entre outros teóricos, foram frutíferas para pensar de que forma essa pesquisa traria a devolutiva social para os sujeitos envolvidos na problemática que conduziu o percurso teórico-metodológico. A opção em definir o lócus a ser pesquisado teve como premissa estabelecer diálogos entre as Artes, a Educação Ambiental e a Formação de Professores, baseada nas indicações dos estudos interdisciplinares que se configuram como "uma dimensão dada ao conteúdo e à prática da educação, orientada para a resolução dos problemas concretos do meio ambiente através de enfoques interdisciplinares" (DIAS, 2004, p. 31).

Destarte, situamos alguns indicativos, dentre eles, estabelecer o lócus e o público a ser convidado para participar do processo de formação. Após essa etapa criou-se a seguinte problemática: De que forma a oficina Arte-educação e Educação Ambiental pode contribuir nas concepções de meio ambiente de futuras pedagogas do município de Ipirá, Bahia?

A escolha por esse grupo específico teve a finalidade de atender uma demanda apresentada pelas próprias atrizes da pesquisa, 25 mulheres, posto que no ano de 2015 ministramos o componente curricular Arte-Educação para uma turma de graduandas em Pedagogia, e em todo o processo formativo as discussões teóricas e empíricas traziam direcionamentos para o campo da Educação Ambiental. Então, resolvemos a partir da oficina, aqui explicitada, inter-relacionar essas duas áreas do conhecimento e traçar desconstruções e construções pautadas nas concepções de Meio Ambiente e Educação Ambiental situadas nos discursos dos teóricos supracitados ao longo dessa produção textual.

\section{PESQUISA-AÇÃO PARTICIPATIVA: PERSPECTIVAS METODOLÓGICAS}

Para atender ao que foi proposto na problemática apresentada neste estudo, seguimos os princípios da Pesquisa-Ação Participativa, a qual tem "por pressuposto que os sujeitos que nela se envolvem compõem um grupo com objetivos e metas comuns, interessados em um problema que emerge num dado contexto no qual atuam" (PIMENTA, 2006, p. 2). 
Nesse movimento, Brandão e Borges (2007) dialogam com as inferências de Pimenta, mas conseguem trazer com ênfase a aplicabilidade da referida metodologia no campo da Educação Ambiental, ao destacarem que:

As alternativas participativas através da pesquisa abrem-se de maneira múltipla e fecunda a outros campos de ação social. Um deles, e um dos mais enfatizados hoje em dia, é o das pesquisas e ações ambientalistas. De fato, o campo das ações ambientais é onde, com mais criatividade, se multiplicam experiências de investigações participativas associadas a alguma forma de ação comunitária (p. 57)

Pensar a proposta de oficina pedagógica associada a essa metodologia proporcionou diferencial, tanto no decorrer das atividades, quanto no período posterior. Nessa abordagem as atrizes sociais são convidadas a ser atuantes e não meras reprodutoras dos ideais hegemônicos da racionalidade ocidental. $\mathrm{O}$ sucesso da oficina parte da entrega e responsabilidade individual, mas com foco no coletivo, posto que as rupturas necessárias só se fecundam a partir das movimentações grupais.

Elaborar a oficina demandou uma estratégia que obedece a carga horária de 8 horas, divididas em dois momentos, manhã e tarde. No primeiro turno, iniciamos com o trabalho de identificar o conhecimento prévio das graduandas acerca do que entendiam sobre Educação Ambiental e Meio Ambiente. A possibilidade de permitir a oralidade dos saberes prévios considerou os ensinamentos de Paulo Freire (1985), para o qual todo indivíduo traz consigo uma gama de conhecimentos os quais devem ser levados em consideração pelos educadores e a partir desses conhecimentos criar os temas geradores das aulas/encontros, pois "no fundo, esse conjunto de representações de situações concretas possibilitava aos grupos populares uma 'leitura' da 'leitura' anterior do mundo, antes da leitura da palavra" (FREIRE, 1985, p. 23).

Acrescido a essa ideia de Freire, a produção teórica de Loureiro (2004) destaca que os temas geradores são relevantes, mas ao transpor para o campo ambiental existe a necessidade de não findar a dialética pedagógica apenas na microescala, como ele elucida:

Por outro lado, por mais que se admita a relevância pedagógica como etapa inicial do educar, não cabe ficar no plano da sensibilização, do reconhecimento do ambiente de vida, da ação no universo particular e de alterações de comportamentos individuais, como coisas válidas em si e suficientes para transformações societárias. É preciso articular a cotidianidade ao macrossocial, em uma atuação política que gere as transformações individuais e coletivas, simultaneamente, e a possibilidade de as experiências localizadas que foram bem-sucedidas se universalizarem (p. 133). 
É justamente essa preocupação que conduziu os diálogos durante a oficina, optando-se por propor discussões que trouxessem entraves locais, mas que, ao mesmo tempo, fossem correlacionados com esferas globais. Assim como Loureiro (2004), entendemos que a articulação global é indispensável para se pensar novas propostas de sustentabilidades.

Caminhando pelos processos metodológicos, ainda no primeiro momento, apresentamos algumas concepções de Meio Ambiente e Educação Ambiental, com destaque para Reigota (2009) e Medida (1997), autores que trazem para o bojo das discussões as complexidades produzidas na dicotomia homem e natureza. Para permear as proposições e provocar embates, apresentamos Boaventura (2002), sobretudo o seu texto Para uma sociologia das ausências e uma sociologia das emergências, responsável por destacar de forma elucidativa as ações, padronizações e ideologias enraizadas na nossa sociedade e, enquanto não as desarticularmos, teremos uma civilização pautada na segregação, exclusão, silenciamento e exploração dos menos favorecidos.

No segundo momento, turno vespertino, apresentamos algumas intervenções avaliadas como bem-sucedidas, implementadas em espaços escolares e não escolares. Percebemos que, em todas as propostas, as Artes estavam interligadas ao campo da Educação Ambiental. Reforçamos o protagonismo juvenil a partir de alguns exemplos: William Kamkwamba: Como eu dominei o vento; Tecnologia social para quebra de coquinho de licuri; Secador econômico para desidratação de tomates desenvolvido por estudantes baianos.

Apresentar essas propostas bem-sucedidas motivou as futuras pedagogas a pensar de que forma poderiam provocar ações similares em seus locus. Nesse limiar, a turma se dividiu em seis equipes, com a solicitação que começassem a projetar no papel as ideias iniciais de um projeto de intervenção, o qual não necessitaria ser aplicado. Contudo, para a nossa surpresa, um dos grupos se prontificou em pôr em prática a sua proposta de intervenção.

A sequência foi elaborada e implementada por três graduandas que escolheram uma localidade chamada Pau Ferro, distrito do município de Ipirá (Figura 1), como campo de intervenção. Sobre a escolha do público-alvo, no relatório encaminhado para a avaliação elas relatam:

Apresentamos o público alvo de nosso plano de Intervenção, o qual pertence a família de baixa renda, vulneráveis socialmente, assistidos pelo Programa Bolsa Família. Nesta perspectiva objetivamos compor um espaço social para estas crianças e proporcionar momentos lúdicos 
através do lazer com brinquedos feitos a partir de materiais recicláveis (Fonte: Relatório de Intervenção).

FIGURA 1 - Município de Ipirá, Bahia. Distrito Pau Ferro.

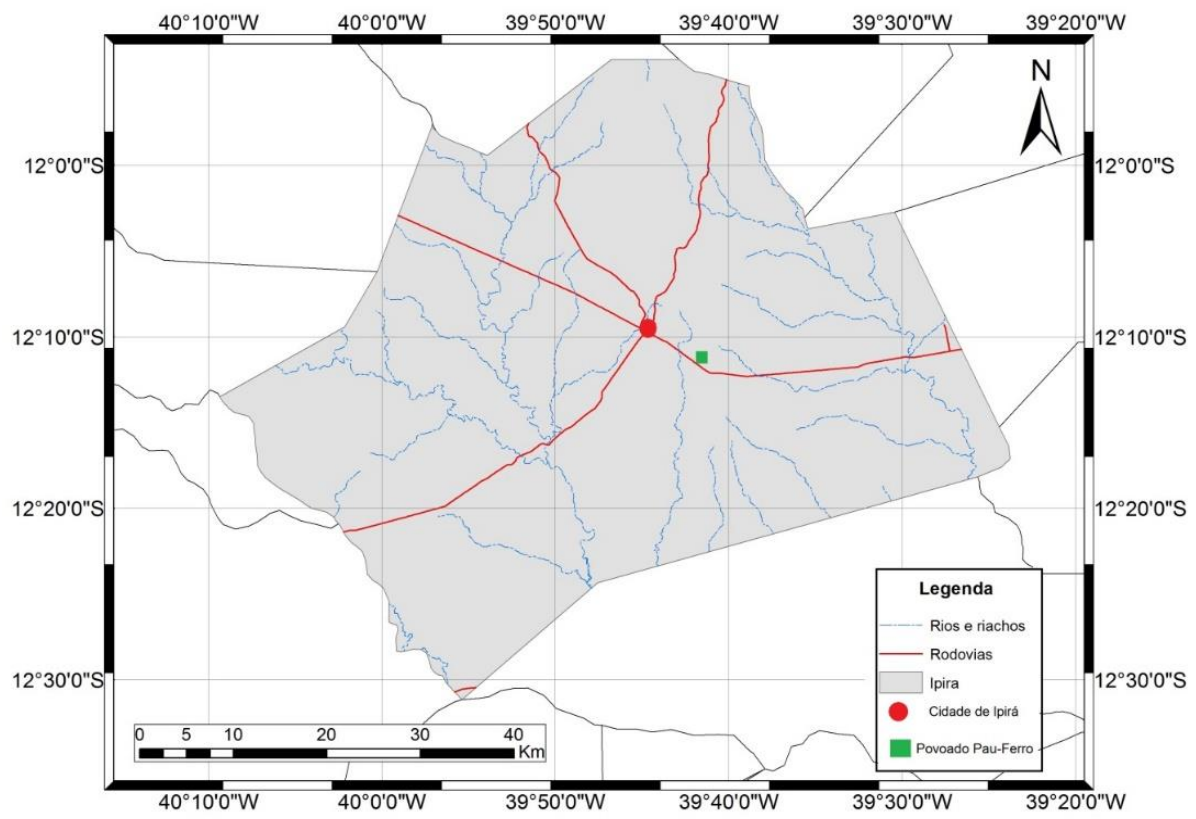

FONTE: Arquivo Pessoal.

Para expor as suas representações sobre a prática desenvolvida com crianças do Pau Ferro, solicitamos que as três atrizes respondessem a um questionário com interpelações dissertativas. Esse instrumento de produção de dados oportunizou verificar de que forma a oficina Arte-educação e Educação Ambiental, atrelada à prática de intervenção, contribuiu com a formação docente das envolvidas.

A análise do material articulado durante a feitura da oficina, bem como do questionário e do relatório referente à intervenção não obedeceram a uma linearidade temporal e muito menos hierárquica. A análise vem sendo tecida desde o processo de conceber a oficina, produzida com as atrizes, abrindo espaços para intervenções. A soma de todos esses dispositivos nos leva a compreender a totalidade, sem a condicionada fragmentação da ciência tradicional.

\section{INTERVENÇÕES: PELO NÃO DESPERDÍCIO DAS EXPERIÊNCIAS}

Abrir espaço para o diálogo é o que tem motivado a nossa prática educativa, acreditamos que tal ação retira o educando do campo da invisibilidade. Constrói-se um espaço afetivo e aplausível para a frutificação de uma gama de saberes, os quais nem sempre são validados pelas linhas de pensamento da academia. 
Por esses veios, destacamos a aplicabilidade da Pesquisa-Ação Participante pelo fato de a mesma ser um dispositivo de mobilização, provocação, produção coletiva. Essa prática estabelece uma variável de territórios fecundos de experiências e evita o que Boaventura (2002) chama de desperdício das experiências.

Dessa forma, essa parte da produção textual será dividida em dois blocos: a aplicabilidade da intervenção e percepções pós-intervenção.

\section{- A aplicabilidade da intervenção}

O trabalho de intervenção proposto pelas graduandas trouxe, desde o início, como elas apontaram no relatório, as contribuições de Paulo Freire, com destaque para a citação: "Quem ensina aprende ao ensinar. E quem aprende ensina ao aprender" (1998, p. 25). Com essa prerrogativa, traçaram a seguinte inquietação: Como utilizar as Artes Sustentáveis como instrumento de inclusão social das crianças de 5 a 8 anos do Povoado Pau Ferro no Município de Ipirá no Estado da Bahia?

Verifica-se a necessidade de incluir, através das Artes Sustentáveis, crianças que socialmente estão enquadradas na zona de desprestígio social, cultural, econômico e educacional. Pensar nas mazelas sociais que afetam essas crianças nos reporta ao conceito de sustentabilidade proferido por Jacobi (1999, p. 180), que afirma:

A sustentabilidade como novo critério básico e integrador precisa estimular permanentemente as responsabilidades éticas, na medida em que a ênfase nos aspectos extra econômicos serve para reconsiderar os aspectos relacionados com a equidade, a justiça social e a ética dos seres vivos.

Nesse intento, por questões sensibilizadas durante a nossa oficina, as graduandas reforçaram o interesse em destacar a relevância das Artes na formação dos cidadãos críticos, como apontam no relatório:

Por isso, a arte é de suma importância para as crianças da educação infantil, pois aguçam o senso critico, quando bem mediada e aflora a sensibilidade exteriorizando as emoções dessas crianças. Partindo desse pressuposto que desenvolvemos nossa intervenção para trabalhar as formas com que as crianças se veem através de Artes Sustentáveis (Fonte: Relatório de Intervenção).

De acordo com essa evidenciação, encontramos, nos Parâmetros Curriculares Nacionais de Artes, a inferência de que o trabalho artístico potencializa o despertar dos educandos para questões que requerem criticidade local e global. Nesse fluxo, deve-se 
inserir os temas geradores e transversais aplicados ao Meio Ambiente:

O conhecimento da arte abre perspectivas para que o aluno tenha uma compreensão do mundo na qual a dimensão poética esteja presente: a arte ensina que é possível transformar continuamente a existência, que é preciso mudar referências a cada momento, ser flexível. Isso quer dizer que criar e conhecer são indissociáveis e a flexibilidade é condição fundamental para aprender. (BRASIL, 1997, p. 9)

Aliada a essas questões, a proposta das graduandas abarca, mesmo que de forma não intencional, a perspectiva de Espaços Educadores Sustentáveis, os quais buscam manter "uma relação equilibrada com o meio ambiente; compensam seus impactos com o desenvolvimento de tecnologias apropriadas, permitindo assim qualidade de vida para as gerações presentes e futuras" (TRAJBER; SATO, 2010, p. 17). Neste sentido, as futuras pedagogas percebem a escola como territorialidade, cujos educandos devem ser acolhidos sem distinções e estimulados à construção da cidadania crítica:

\begin{abstract}
Através disso podemos desenvolver oficinas de Artes Plásticas nas confecções de brinquedos com materiais recicláveis pelo fato de contribuir com o desenvolvimento infantil, pois trabalhar com materiais do cotidiano deles amplia a imaginação e a criatividade das crianças, assim eles serão estimulados e motivados, pois sabemos que a educação infantil tem como objetivo acolher todas as crianças independente de suas condições. Então, devemos nos preparar para receber esses sujeitos e assim construir um espaço onde propicie a diversidade (Fonte: Relatório de Intervenção).
\end{abstract}

Destarte, a aplicabilidade da intervenção objetivou a confecção de dois brinquedos a partir de materiais plásticos descartáveis, os quais foram ressignificados e originaram um instrumento musical - Tambor - (Figura 2 e 3), assim como o brinquedo "Passa a bolinha" (Figura 4):

FIGURA 2 e 3 - Produção do instrumento musical Tambor.
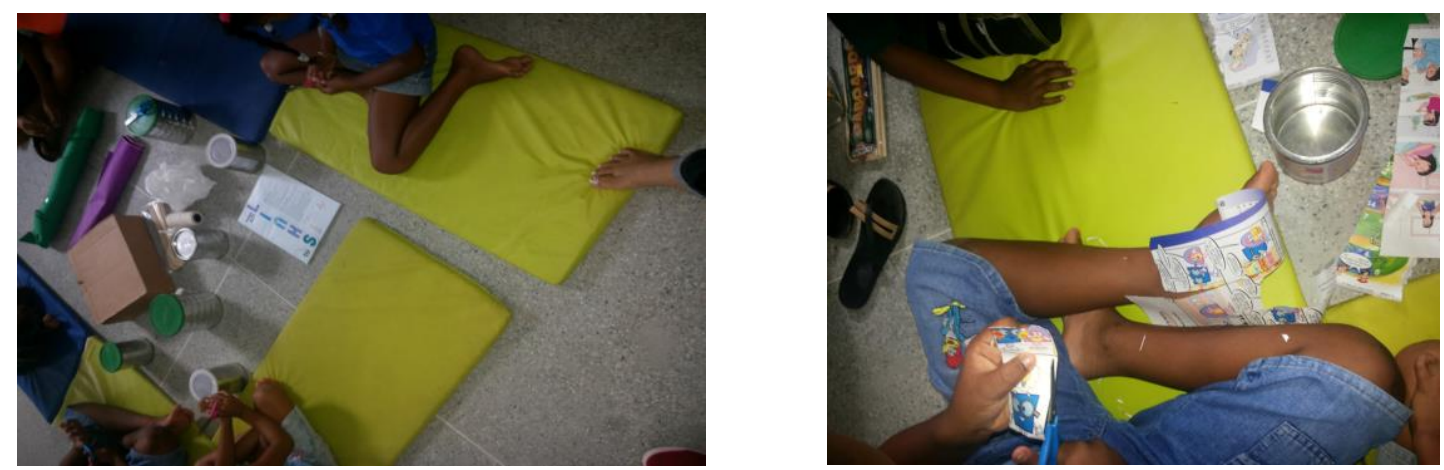

FONTE: Relatório de Intervenção. 
FIGURA 4 - Confecção do brinquedo "Passa a bolinha".

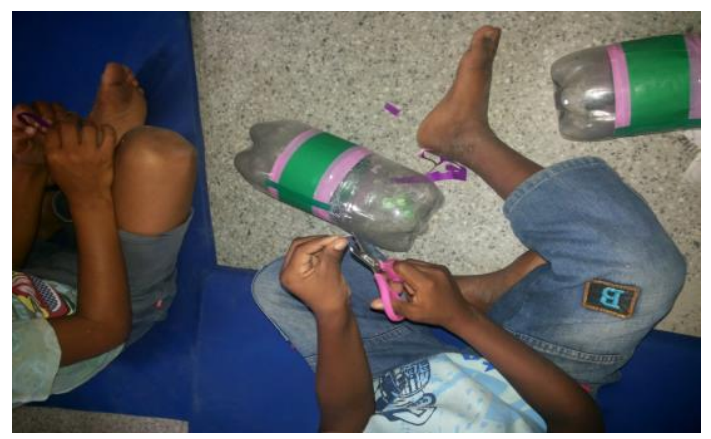

FONTE: Relatório de Intervenção.

Ao descrever a atividade, as futuras pedagogas apontaram a afetividade como uma estratégia para conquistar a atenção dos educandos, bem como proporcionar o encantamento pela atividade prática que estava por ser elaborada. Contudo, relataram que iniciaram a intervenção:

Falando sobre a importância de reutilizar alguns materiais que iriam para o lixo, neste primeiro dia optamos por fazer juntos com eles um tambor com latas de leite em pó eles adoraram a ideia, mostramos para eles que a partir de uma lata vazia poderíamos fazer um instrumento musical. (Fonte: Relatório de Intervenção).

Sobre essa ação, inferimos que o discurso utilizado está orientado na concepção comportamentalista, cujo debate pauta-se no campo da superficialidade de mudanças no comportamento e descarta-se a problematização da produção de lixo, o consumo excessivo, o contexto histórico desencadeador das decisões contemporâneas. Segundo Carvalho (2001, p.46):

Uma outra ideia bastante recorrente nesta perspectiva é a de que, embora todos os grupo sociais devam ser educados para a conservação ambiental, as crianças são um grupo prioritário. As crianças representam aqui as gerações futuras em formação. Considerando que as crianças estão em fase de desenvolvimento cognitivo, supõe-se que nelas a consciência ambiental pode ser internalizada e traduzida em comportamentos de forma mais bem sucedida do que nos adultos que, já formados (...).

No decorrer da leitura do relatório de intervenção, percebemos um amadurecimento das concepções de Meio Ambiente e Educação Ambiental. Em alguns momentos, as transcrições se aproximam da abordagem socioambiental, em outros a concepção comportamental, sobretudo no que tange à mudança de comportamento que 
é creditada na formação das crianças. Tal oscilação é fruto do processo no qual as futuras docentes estão inseridas. Ou seja, a desconstrução de inúmeras certezas e verdades para iniciar um ciclo com a consolidação de estratégias e dispositivos que, de fato, proporcionem a superação da dicotomia entre homem e natureza e, a partir disso, alcançar as rupturas pedagógicas necessárias para a efetivação da Educação Ambiental revolucionária, crítica e sustentável.

\title{
- Percepções pós-intervenção
}

O segundo bloco busca compreender de que forma a oficina Arte-Educação $e$ Educação Ambiental, associada à prática de intervenção, contribuiu para a identidade docente das graduandas envolvidas no processo de formação. Para tal, existe a necessidade de buscar uma evidenciação do que seja formação. Para Marcelo García (1999, p. 26):

\begin{abstract}
A formação de professores é a área de conhecimento, investigação e de propostas teóricas e práticas que, no âmbito da Didática e da Organização Escolar, estuda os processos através dos quais os professores - em formação ou em exercício - se implicam individualmente ou em equipe, em experiências de aprendizagem através das quais adquirem ou melhoram os seus conhecimentos, competências e disposições, e que lhes permite intervir profissionalmente no desenvolvimento do seu ensino, do currículo ou da escola, com o objetivo de melhorar a qualidade da educação que os alunos recebem.
\end{abstract}

Delinear a formação com base nas experiências é o que desperta o nosso interesse em trabalhar com a pesquisa-ação participante, ainda mais no caso de alunos em formação inicial. Para verificar como ocorreu a repercussão da intervenção nas subjetividades de cada uma das envolvidas, aplicamos um questionário com 4 questões dissertativas. Na primeira questão, a seguinte interpelação: Qual a sua concepção sobre Meio Ambiente e Educação Ambiental antes de aplicar a Oficina no Pau Ferro? A graduanda Borboleta ${ }^{5}$ declarou:

Não tinha uma concepção de meio ambiente mas aprendi no ensino fundamental que o Meio ambiente é todo o espaço terrestre que envolvesse as coisas vivas e não-vivas, como os microrganismos. E que a educação ambiental seria o processo educacional para se despertar os alunos para as questões do meio ambiente.

\footnotetext{
${ }^{5}$ Nomes fictícios foram utilizados para respeitar a identidade original das atrizes envolvidas na pesquisa. Solicitamos que escolhessem um nome e que fossem explicitados o motivo pela opção. Borboleta - Por ser um animal lindo que faz parte do meio ambiente e é livre, sem contar o processo que ela passa para se tornar uma borboleta.
} 
Analisar essa resposta leva-nos a perceber o poder da Educação Básica, com ações que podem reverberar ideologias críticas ou simplesmente reafirmar posicionamentos equivocados. O posicionamento de Borboleta traz a concepção natural de meio ambiente (TOZONI-REIS, 2004), a qual reafirma o homem enquanto o vilão da natureza intocada. No que tange à Educação Ambiental, segue a mesma linha teórica e, de acordo com Medina (1994), elucida a vertente preservacionista.

Em relação à segunda pergunta, Qual a sua concepção de Meio Ambiente e Educação Ambiental depois de aplicar a Oficina no Pau Ferro? A outra participante, Amora $^{6}$, destaca:

Após a oficina, a minha visão com relação aos materiais recicláveis ficou mais apurada e o entendimento da importância de reciclar estes materiais e assim tornar mais divertido o dia das crianças daquele povoado tornou o trabalho mais prazeroso e significativo.

Constatamos, a partir da resposta, que, apesar das discussões durante a oficina Arte-Educação e Meio Ambiente, a Amora reproduz um discurso que transita entre duas concepções de meio ambiente: cognoscente e sócio-histórica (TOZONI-REIS, 2004). A cognoscente representa o conhecimento como mediador da relação mecânica, direta e fria entre homem-natureza, em que se encaixa a questão de saber que reciclar é importante, posto que é um discurso formatado, de rápido compreensão, mas com tamanha simplicidade que não contribui para rupturas significativas. Já a sócio-histórica abarca as demandas culturais, econômicas e políticas da relação homem-natureza, na qual a condições de precariedade social afeta a vida das crianças da localidade estudada, e isso tem um rebatimento na constituição sócio-histórica.

Continuando o questionário, alcançamos a terceira pergunta: Realizar a intervençãoloficina na Comunidade de Pau Ferro apresentou alguma relevância na sua formação docente? Justifique. Vejamos a explanação de Borboleta:

Sim. Pois pude perceber como é importante trabalhar com as vivencias dos alunos em sala de aula e o conhecimentos prévio dos mesmos, o trabalho fica muito mais gratificante.

Tal posicionamento exprime as condições necessárias para o educador que compreende o educando como um ser dotado de saberes, experiências e possibilidades

\footnotetext{
${ }^{6}$ A opção Amora foi justificada por ser o codinome utilizado sempre que necessário.
} 
construtivas. É justamente essa postura que pode levar a educação básica a construir práticas interculturais e, consequentemente, a Educação Ambiental efetiva e transformadora, já que a escola é "um local privilegiado de troca de ideias, de encontros, de legitimação de práticas sociais, de interação entre gerações, de articulação entre diversos padrões culturais e modelos cognitivos" (TURA, 2002, p. 156).

Na quarta e última questão: Pretende, ao finalizar a graduação em Pedagogia, associar o ensino de Artes com a Educação Ambiental? Como afirmação, Amora repercutiu:

Sim. Pois foi o que foi feita nesta intervenção no povoado do Pau-ferro, foi trabalhada a importância do meio ambiente com a preservação na utilização dos materiais reciclados transformados em brinquedos. Foi feito o ensino de artes com a educação ambiental.

Verificamos a potência do discurso de reciclagem, mas sem nenhum tipo de relação com os processos históricos, sociais, subjetivos, políticos e com o descrédito a "uma reflexão crítica e abrangente a respeito dos valores culturais da sociedade de consumo, do consumismo, do industrialismo, do modo de produção capitalista e dos aspectos políticos e econômicos da questão do lixo" (LAYARGUES, 2002, p. 179). Constatamos que a publicização da ideologia da reciclagem tem imenso apelo perante as argumentações da maioria dos educadores que transitam pelos espaços nos quais realizamos formações docentes.

As duas entrevistadas não abarcam a totalidade de todos os graduandos em formação, porém é inquestionável que o conhecimento sobre Educação Ambiental e Meio Ambiente elucidado nas graduações tem forte ligação com as perspectivas traçadas nos livros didáticos da Educação Básica, assim como nas metodologias dos educadores que se propõem a inserir nos planos de aulas a transversalidade da temática.

\section{CONSIDERAÇÕES: RUPTURAS E CONTINUIDADES}

Articular essa produção textual demandou uma reflexão sobre o período que nos dedicamos à temática da Educação Ambiental. Nesse processo de reflexão, verificamos o quão necessário é o desencadeamento do (des)construir para iniciar um ciclo e traçar perspectivas frutíferas.

Constatamos a perversidade que está instalada em todos os setores da nossa 
sociedade, sobretudo no campo da Educação. Consideramos perversas a soberania e perpetuação de ideologias que reforçam a segregação e exploração, com a finalidade de atender ao imperialismo capitalista.

A educação básica e o ensino superior são utilizados para reproduzir os saberes instaurados pelos grupos hegemônicos, os mesmos responsáveis por reforçar a dicotomia hierarquizada entre homem e natureza. Boaventura (2006) nos diz que esse viés é típico da racionalidade ocidental, cujas ações prezam pela aniquilação das diferenças e a implantação de padrões sociais.

Nessa perspectiva de homogeneizar, a Educação Ambiental acaba sendo trabalhada de forma equivocada e quase sempre desacreditada. Associa-se a esse campo do saber práticas pontuais e com escalas específicas, negando-se as possibilidades de interconexões globais.

Portanto, ao propor a oficina Arte-Educação e Educação Ambiental, tivemos a intencionalidade de socializar os saberes acumulados. Não intentamos, com a oficina, sanar todas as problemáticas ou criar seguidores com os mesmos ideais. Muito pelo contrário, tivemos como meta principal ouvir, entender, aproximar e compreender como aquelas atrizes percebiam a temática em voga. Por diversas vezes, vimo-nos em seus argumentos, nas falas equivocadas, nas certezas infundadas, enfim, nas prerrogativas ideológicas dos discursos hegemônicos.

Concluímos essa produção textual com a certeza de que muito precisa ser feito para que tantos outros educadores em formação inicial ou continuada desvelem os conhecimentos deturpados e reafirmem os saberes frutíferos de críticas, transformações e rupturas.

Recebido em: 23-02-2018 Aceito em: 25-03-2018

\section{REFERÊNCIAS}

BAUMAN, Zygmunt. Modernidade líquida. Rio de Janeiro: Jorge Zahar Ed., 2001.

BRANDÃO, Carlos Rodrigues; BORGES, Maristela Correa. A pesquisa participante: um momento da educação popular. Rev. Ed. Popular, Uberlândia, v. 6, p. 51-62. jan./dez. 2007.

BRASIL. Secretaria de Educação Fundamental. Parâmetros curriculares nacionais: arte / Secretaria de Educação Fundamental. - Brasília, 1997.

CAMARGO, Ana Luiza de Brasil. Desenvolvimento sustentável: dimensões e desafio. 
Campinas, SP: Papirus, 2003.

CARVALHO, Izabel. Cristina de Moura. Educação ambiental: a formação do sujeito ecológico. 2. ed. São Paulo: Cortez, 2006.

CHAUÍ, Marilena. Natureza, cultura, patrimônio ambiental. In: DUARTE, Ana Lúcia (Coord.). Meio ambiente: patrimônio cultural da USP. São Paulo: Editora

Universidade de São Paulo; Imprensa Oficial do Estado de São Paulo; Comissão de Patrimônio Cultural, 2003.

DIAS, Genebaldo Freire. Educação Ambiental: princípios e práticas. 5. ed. São Paulo: Gaia, 2004.

FREIRE, Paulo. A importância do ato de ler. São Paulo: Cortez/Autores Associados, 1985.

FREIRE, Paulo. Pedagogia da autonomia saberes necessários à prática educativa. 8. ed. Rio de Janeiro: Paz e Terra. 1988.

GARCÍA, Carlos. Pesquisa sobre a formação de professores. O conhecimento sobre aprender a ensinar. Faculdade de Ciências da Educação, Universidade de Sevilha. Tradução de Lólio Lourenço de Oliveira. Trabalho apresentado na XX Reunião Anual da ANPEd, Caxambu, setembro de 1998.

JACOBI, Pedro. Meio ambiente e sustentabilidade. In. Fundação Prefeito Faria Lima CEPAM. O município no século XXI: cenários e perspectivas. São Paulo: Especial, 1999. p. 185-190.

KUHN, Thomas. A Estrutura das Revoluções Científicas. $2^{a}$ ed. São Paulo: Editora Perspectiva, 1978.

LAYARGUES, Philippe. O cinismo da reciclagem: o significado ideológico da reciclagem da lata de alumínio e suas implicações para a educação ambiental. LOUREIRO, Carlos Frederico Bernardo; LAYARGUES, Philippe; CASTRO, Ronaldo Souza. (Orgs.) Educação ambiental: repensando o espaço da cidadania. São Paulo: Cortez, 2002, p. 179-220.

LOUREIRO, Carlos Frederico Bernardo. (Org.) Cidadania e meio ambiente. Salvador: Centro de Recursos Ambientais, 2003.

LOUREIRO, Carlos Frederico Bernardo. Trajetórias e fundamentos da educação ambiental. São Paulo: Cortez, 2004.

MEDINA, Naná Mininni. Educação ambiental para o século XXI e a construção do conhecimento: suas implicações na educação ambiental. Brasília: Editora, 1997.

PIMENTA, Selma Garrido. Pesquisa-ação crítico-colaborativa: construindo seu significado a partir de experiências na formação e na atuação docente. PIMENTA, Selma Garrido; GHEDIN, Evandro., FRANCO, Maria Amélia Santoro (Org.). Pesquisa em educação: alternativas investigativas com objetos complexos. São Paulo: Loyola, 2006.

REIGOTA, Marcos. O que é educação ambiental. São Paulo: Brasiliense, 1994. 
SANTOS, Boaventura de Souza. A gramática do tempo: para uma nova cultura política. São Paulo: Cortez, 2006.

SANTOS, Milton. Do meio natural ao meio técnico-científico-informacional. In: A natureza do espaço. São Paulo: Hucitec, p.187-197, 1996.

SORRENTINO, Marcos et al.. Educação ambiental como política pública. Educação e Pesquisa, São Paulo, v. 31, n. 2, p. 285-299. 2005.

TOZONI-REIS, Marília Freitas de Campos. Educação ambiental: natureza razão e historia. Campinas, SP: Autores associados, 2004.

TRAJBER, Rachel. SATO, Michele. Escolas sustentáveis: incubadoras de transformações nas comunidades. Revista Eletrônica do Mestrado em Educação Ambiental (FURG). Vol. Especial, setembro de 2010.

TURA, Maria de Lourdes Rangel. Conhecimentos escolares e a circularidade entre culturas. In: LOPES, Alice Casimiro; MACEDO, Elizabeth. (Org.). Currículo: debates contemporâneos. São Paulo: Cortez, 2002. 